\title{
Pre-formulation Studies on Moisture Absorption in Microcrystalline Cellulose Using Differential Thermo-Gravimetric Analysis
}

\author{
Paul Wan Sia Heng, ${ }^{*}$ Celine Valeria Liew, and Josephine Lay Peng SoH \\ Department of Pharmacy, National University of Singapore; 18 Science Drive 4, Singapore 117543. \\ Received September 24, 2003; accepted January 14, 2004
}

\begin{abstract}
A study on the differential thermo-gravimetric (DTG) measurements of microcrystalline cellulose (MCC) containing moisture indicated that particle size affected the amount of bound water and the flow indices. Thermal analysis of 6 commercial grades of MCC powders and MCC/water blends were performed using a thermogravimetric analyzer. These MCCs were differentiated by their particle size, bulk and tapped densities, crystallinity and micromeritic properties. From the DTG curves, it was observed that water loss from the MCC/water blends occurred in 3 phases which corresponded to the different states of water associated with the solid particles. Area under the third phase, or the falling rate phase, can be associated with the release of water that was physically shielded or bound to the solid. This water may be referred to as "structured" water. The large particle size grades of MCC-Avicel PH 102, PH 302 and Pharmacel 102 were found to possess smaller quantities of structured water. Water vapor sorption results revealed the monolayer capacities for the respective MCC grades. The amount of structured water appeared to correspond to the existence of bilayers on the surface of the small particle size MCC grades. Using the avalanche flow assessment method, flow properties of small particle size grades of MCC were found to be poorer as indicated by the significant correlation between their flow indices and size, in addition to the longer mean times to avalanche.
\end{abstract}

Key words thermogravimetry; microcrystalline cellulose; water sorption; particle size; powder avalanche

An excipient of considerable interest to the pharmaceutical industry is microcrystalline cellulose (MCC). MCC plays a critical and almost indispensable role in the production of spheroids containing drugs. Spheroids are highly desirable as they have defined surface areas and are best suited for the development of controlled release products. Besides, they possess excellent bulk handling and processing properties because of good flow properties and low friability.

It is not fully understood how or why MCC possesses such unique qualities to facilitate the process of spheronisation. However, it is widely believed that it acts like a molecular sponge or water repository that helps to distribute water during spheronisation and, in turn, enable the extrudates to be rounded off into spheroids. ${ }^{1)}$

Inter-grade variability of MCC has been well-documented and much of this was attributed to the differences in the source, composition of plant material and processing conditions employed in its manufacture. ${ }^{2-6)}$ This variability is subsequently reflected as differences in their fundamental physical properties, such as particle size and size distribution, crystallinity, micromeritic properties and compressibility parameters such as bulk and tapped densities. The resultant inconsistencies in quality of starting materials compromised control of process parameters during pharmaceutical manufacture, causing considerable loss of time and resources due to products that fail to meet specifications. The importance of pre-formulation studies could not be over-emphasized.

Common thermal analytical techniques include differential thermo-gravimetry (DTG), differential thermal analysis (DTA) and differential scanning calorimetry (DSC). DTG provides quantitative analysis of the reactions by measuring the change in weight while DTA measures the temperature difference between the reference and the test sample. DSC on the other hand measures the heat flow in and out of the sample. Pharmaceutical applications of thermal analysis and coupled techniques were studied by Giron. ${ }^{7)}$ The important uses of techniques such as DSC, DTG and DTA included identification, purity determination and study of polymorphism in bioactive and excipients.

The study of water-MCC interaction has been pursued with great interest over the years. ${ }^{8-10)}$ Thermal behavior of MCC, MCC/water or MCC/lactose/water blends using DTG has been reported by a few researchers. ${ }^{11,12)}$ It was found that particle size influenced the degree of water binding ability between the different MCC grades. Particle morphology such as particle size and shape, surface area and surface roughness can also be critical in influencing the strength of cohesive forces acting on the powder particles. ${ }^{13)}$

Water was believed to associate with celluloses in a triphasic process. Firstly, water binds to adjacent anhydroglucose units of the MCCs, forming 2 hydrogen bonds in the process. As the water content increases, some of the initial bonds between water and the cellulose molecules would be broken, vacating some of the anhydroglucose units for binding with the newly added water molecules. When the available binding sites are saturated with water molecules, further addition of water will result in the formation of hydrogen bonds between water molecules. ${ }^{11)}$ The portions of water associated with the 3 phases are referred to as tightly bound, loosely bound and free or bulk water respectively. The actual amount of water taken up by MCCs is dependent on many physical and surface properties, to varying extents. In particular, the effects of surface area and particle size were pursued with keen interest in this study. The inter-relationships between particle size and surface with moisture adsorption and flow were studied. The advantages and usefulness of differential thermo-gravimetric analysis in quantifying the degree of water binding in wet powder mixes will be discussed.

\section{Experimental}

Materials Six grades of MCC were used: Avicel PH 101, Avicel PH 102, Avicel PH 301, Avicel PH 302 (Asahi, Osaka, Japan), Pharmacel 101 and Pharmacel 102 (DMV, Veghel, The Netherlands). Determined character- 
istics of these MCCs had been previously reported ${ }^{14)}$ and reproduced in Table 1.

Physical Characterization of MCC Grades Particle size $(\bar{X})$, bulk $\left(\rho_{\mathrm{b}}\right)$ and tapped $\left(\rho_{\mathrm{t}}\right)$ densities, crystallinity $\left(X_{\mathrm{cr}}\right)$ and micromeritic parameters $\left(V_{\text {lowP }}, V_{\text {highP }}, V_{\text {total }}\right.$ and $\varepsilon$ ) were previously determined. ${ }^{14)} V_{\text {lowP }}$ was the specific cumulative intruded mercury volume into the pores as pressure was increased from $0-0.172 \mathrm{MPa} ; V_{\text {highp }}$ denoted the specific cumulative intruded mercury volume into intraparticulate pores between $10-0.006 \mu \mathrm{m}$ as the pressure was increased from $0.172-207 \mathrm{MPa} ; V_{\text {total }}$ was the total specific intrusion volume for the pores in the entire pressure range from $0-207 \mathrm{MPa}$ and was calculated as the sum of $V_{\text {highP }}$ and $V_{\text {lowP }}$ whereas $\varepsilon$ denoted the percent porosity.

Preparation of Wet Granulates Fifteen grams of MCC powder were loaded into the mixer bowl of a mixer torque rheometer (MTR, Caleva, Sturminster Newton, U.K.). Distilled water was added in a ratio of $1: 1(\mathrm{w} / \mathrm{w})$ to the dry powder and mixed for $20 \mathrm{~min}$. This MCC/water blend produced was used for the subsequent analysis and would be referred to as wet granulates henceforth.

Thermo-Gravimetry of Wet Granulates The drying profiles of the wet granulates were determined by DTG (DTG 60H, Shimadzu, Kyoto, Japan). An alumina crucible was filled to two-third full with the granulate to ensure the formation of a granulate layer in the crucible. Measurements began immediately after filling. The weights of granulate used ranged from 10 $25 \mathrm{mg}$, depending on the densities of the MCC grades used. Drying progressed at a rate of $5{ }^{\circ} \mathrm{C} / \mathrm{min}$ from 28 to $105^{\circ} \mathrm{C}$ under a $\mathrm{N}_{2}$ environment. The test was repeated thrice and the variation between runs were found not to be significant [analysis of variance (ANOVA), $p>0.05$ ].

Determination of Percent Structured Water of the MCC Grades, \% $\mathbf{H}_{2} \mathbf{O}_{\text {(s) }}$ DTG curves were analogous to the drying profiles of the wet granulates. Using the trapezium rule, the area under the falling rate phase of the DTG curves were integrated from the start of the falling rate phase until the point of completion of the drying. This area corresponded to the amount of water that was physically hindered or bound to the surface of the powder, or the amount of structured water, $\mathrm{H}_{2} \mathrm{O}_{(\mathrm{s})}$. The $\% \mathrm{H}_{2} \mathrm{O}_{(\mathrm{s})}$ was calculated as the quotient of $\mathrm{H}_{2} \mathrm{O}_{(\mathrm{s})}$ to the dry weight of the $\mathrm{MCC}$ powders used, expressed as a percentage.

$$
\% \mathrm{H}_{2} \mathrm{O}_{(\mathrm{s})}=\frac{\mathrm{H}_{2} \mathrm{O}_{(\mathrm{s})}}{W_{\text {granulates }}-W_{\text {water }}} \times 100 \%
$$

where $\mathrm{H}_{2} \mathrm{O}_{(\mathrm{s})}$ is the weight of structured water, $W_{\text {granulates }}$ is the weight of wet granulate and $W_{\text {water }}$ is the weight of water added to the MCC powders.

Sorption Isotherms The sorption isotherms for the 4 Avicel MCC grades were determined with a dynamic vapor sorption (DVS) apparatus (DVS-1, Surface Measurement Systems, U.K.). The MCC powders were pre-dried at $105^{\circ} \mathrm{C}$ for $4 \mathrm{~h}$ in a hot air oven. Ten milligrams of MCC powder were used for each run. The percent relative humidity $(\% \mathrm{RH})$ was allowed to increase from 0 to 100 in 10 steps of $10 \% \mathrm{RH}$ each. The rate of change of mass was set at $0.002 \%$. This meant that the rate of change of mass has to be lesser than or equal to $0.002 \%$ before the system is considered to be equilibrated at this RH.

The temperature for the experiment was maintained at $25^{\circ} \mathrm{C}$ throughout. Absorption cycles were performed in triplicates for each grade of MCC.

The monolayer capacity for the sorption cycle, $M_{\mathrm{o}}$, was calculated using the Guggenheim-Anderson-de Boer equation as shown:

$$
M=\frac{M_{\mathrm{o}} C_{\mathrm{g}} K\left(P / P_{\mathrm{o}}\right)}{\left[1-K\left(P / P_{\mathrm{o}}\right)\right]\left[1-K\left(P / P_{\mathrm{o}}\right)+C_{\mathrm{g}} K\left(P / P_{\mathrm{o}}\right)\right]}
$$

where $M$ is the amount of the gas adsorbed, $P / P_{\mathrm{o}}$ is the relative pressure, $M_{\mathrm{o}}$ is the amount of the adsorbate constituting a monolayer of surface coverage, $C_{\mathrm{g}}$ is the constant related to the heat of sorption and the heat of condensation of water. $K$ is the constant correcting properties of multilayer molecules with respect to the bulk liquid.

Determination of Powder Avalanches Powder avalanches were tested using a powder flowability analyzer (Aero-Flow ${ }^{\mathrm{TM}}$, Model 3250, TSI Incorporated, U.S.A.). The flow analyzer consisted of a transparent cylindrical drum, $150 \mathrm{~mm}$ in diameter fitted on a vertical bayonet-type mount (Fig. 1). The drum could be programmed to rotate at user-defined rates. A metal mesh screen of approximately $60 \%$ open area was placed onto the inner circumference of the drum to prevent the sliding of powder particles down the circumferential wall instead of avalanching. MCC powders were dried at $105^{\circ} \mathrm{C}$ for $4 \mathrm{~h}$ before use. The powders were sieved through a $1 \mathrm{~mm}$ sieve into a $100 \mathrm{ml}$ measuring cylinder to measure out $60 \mathrm{ml}$ of the powder prior to

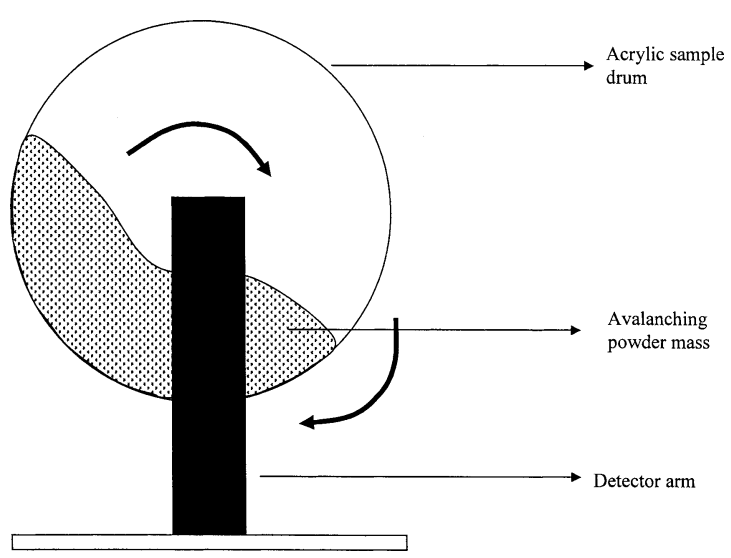

Fig. 1. Diagrammatic Presentation of Aero-Flow ${ }^{\mathrm{TM}}$ (Front View)

each analysis. The analysis was performed at 7 different speeds between 60 to $240 \mathrm{~s}$ per rotation.

The flow properties of the MCC powders were assessed by comparing their strange attractor plots visually. The time difference between each avalanche and the next formed one coordinate point on a scatter plot known as the drawing of attraction. ${ }^{15)}$

The flow index ${ }^{15)}$ was calculated according to the equation shown below:

$$
\text { flow index }=\frac{1}{n} \sum_{i=1}^{n} S_{i}
$$

where $n$ is the total number of speeds tested and $S_{i}$ is the standard deviation of the tested speed.

A small flow index is indicative of good flow.

\section{Results and Discussion}

Thermo-Gravimetric Analysis of Wet Granulates Figure 2 shows the thermal analysis results for the 6 grades of MCC. The drying profiles for the 2 high density grades of MCC were consistently higher than the other 4 grades which may imply that the proportions of moisture present were higher in these 2 grades.

The time taken to lose $50 \%$ of the moisture, $T_{50 \%}$ was determined for each MCC grade (Table 1). ANOVA results showed that there was significant difference in the $T_{50 \%}$ values $(p<0.05)$ between the various MCC grades. Avicel PH 301 and PH 302 lost moisture slower as they possessed higher $T_{50 \%}$ values.

From the differential curves (Fig. 2b), it was observed that the rates of moisture loss occurred in 3 phases. Initially, the drying rates rose steadily and linearly to a maxima and remained constant briefly (constant rate phase) before decreasing (falling rate phase) to the baseline when all the moisture was completely removed from the granulates.

The 3 phases of drying corresponded to the 3 states of water that were associated with the drying of solids. The first phase or the warming phase corresponded to the loss of loosely bound or interstitial water. As this water was mobile and freely available around the solid particles, it was lost most readily when sufficient energy was supplied to heat up and overcome the latent heat of vaporization as indicated by the progressive linear increase in the rate of moisture loss. The linearity corresponded to a constant amount of heat energy supplied.

The constant rate phase coincided with the equilibrium between moisture loss and heat energy supply. This is the steady-state condition commonly seen in bed drying studies 
Table 1. Physical Properties of the Various MCC Grades ${ }^{a)}$

\begin{tabular}{|c|c|c|c|c|c|c|c|c|c|c|c|}
\hline $\begin{array}{l}\text { MCC } \\
\text { grades }\end{array}$ & $\% \mathrm{H}_{2} \mathrm{O}_{(\mathrm{s})}$ & $\begin{array}{l}\text { Flow } \\
\text { index }\end{array}$ & $T_{50 \%}(\mathrm{~s})$ & $\bar{X}(\mu \mathrm{m})$ & $X_{\mathrm{cr}}(\%)$ & $\begin{array}{c}V_{\text {lowP }} \\
(\mathrm{ml} / \mathrm{g})\end{array}$ & $\begin{array}{c}V_{\mathrm{highP}} \\
(\mathrm{ml} / \mathrm{g})\end{array}$ & $\begin{array}{c}V_{\text {total }} \\
(\mathrm{ml} / \mathrm{g})\end{array}$ & $\varepsilon(\%)$ & $\begin{array}{c}\rho_{\mathrm{b}} \\
(\mathrm{g} / \mathrm{ml})\end{array}$ & $\begin{array}{c}\rho_{\mathrm{t}} \\
(\mathrm{g} / \mathrm{ml})\end{array}$ \\
\hline PH 101 & $\begin{array}{c}24.54 \\
(3.74)\end{array}$ & 2.211 & $\begin{array}{c}565 \\
(31.22)\end{array}$ & $\begin{array}{c}76.53 \\
(0.53)\end{array}$ & $\begin{array}{l}69.56 \\
(0.95)\end{array}$ & $\begin{array}{c}1.19 \\
(0.03)\end{array}$ & $\begin{array}{c}0.35 \\
(0.01)\end{array}$ & $\begin{array}{c}1.54 \\
(0.03)\end{array}$ & $\begin{array}{l}65.45 \\
(2.46)\end{array}$ & $\begin{array}{c}0.31 \\
(0.00)\end{array}$ & $\begin{array}{c}0.43 \\
(0.00)\end{array}$ \\
\hline PH 102 & $\begin{array}{l}20.60 \\
(4.18)\end{array}$ & 1.598 & $\begin{array}{c}550 \\
(17.32)\end{array}$ & $\begin{array}{r}132.81 \\
(1.95)\end{array}$ & $\begin{array}{l}69.49 \\
(0.29)\end{array}$ & $\begin{array}{c}1.22 \\
(0.060)\end{array}$ & $\begin{array}{c}0.44 \\
(0.04)\end{array}$ & $\begin{array}{c}1.67 \\
(0.09)\end{array}$ & $\begin{array}{l}66.92 \\
(5.61)\end{array}$ & $\begin{array}{c}0.31 \\
(0.00)\end{array}$ & $\begin{array}{c}0.42 \\
(0.00)\end{array}$ \\
\hline PH 301 & $\begin{array}{l}25.99 \\
(2.49)\end{array}$ & 2.314 & $\begin{array}{c}635 \\
(45.83)\end{array}$ & $\begin{array}{l}73.55 \\
(0.54)\end{array}$ & $\begin{array}{l}76.37 \\
(7.98)\end{array}$ & $\begin{array}{c}0.86 \\
(0.06)\end{array}$ & $\begin{array}{c}0.29 \\
(0.02)\end{array}$ & $\begin{array}{c}1.14 \\
(0.07)\end{array}$ & $\begin{array}{l}61.15 \\
(2.88)\end{array}$ & $\begin{array}{c}0.43 \\
(0.00)\end{array}$ & $\begin{array}{c}0.56 \\
(0.00)\end{array}$ \\
\hline PH 302 & $\begin{array}{l}21.13 \\
(1.03)\end{array}$ & 1.655 & $\begin{array}{c}645 \\
(68.84)\end{array}$ & $\begin{array}{r}139.41 \\
(1.36)\end{array}$ & $\begin{array}{l}84.81 \\
(6.99)\end{array}$ & $\begin{array}{c}0.75 \\
(0.06)\end{array}$ & $\begin{array}{c}0.30 \\
(0.03)\end{array}$ & $\begin{array}{c}1.06 \\
(0.08)\end{array}$ & $\begin{array}{l}60.11 \\
(2.76)\end{array}$ & $\begin{array}{c}0.46 \\
(0.00)\end{array}$ & $\begin{array}{c}0.59 \\
(0.00)\end{array}$ \\
\hline Pharmacel 101 & $\begin{array}{c}29.54 \\
(0.11)\end{array}$ & 2.174 & $\begin{array}{c}545 \\
(22.91)\end{array}$ & $\begin{array}{c}62.24 \\
(0.22)\end{array}$ & $\begin{array}{l}72.371 \\
(2.53)\end{array}$ & $\begin{array}{c}1.11 \\
(0.10)\end{array}$ & $\begin{array}{c}0.49 \\
(0.02)\end{array}$ & $\begin{array}{c}1.60 \\
(0.11)\end{array}$ & $\begin{array}{l}62.30 \\
(0.86)\end{array}$ & $\begin{array}{c}0.30 \\
(0.00)\end{array}$ & $\begin{array}{c}0.44 \\
(0.00)\end{array}$ \\
\hline Pharmacel 102 & $\begin{array}{l}22.60 \\
(0.02)\end{array}$ & 1.787 & $\begin{array}{c}570 \\
(30)\end{array}$ & $\begin{array}{r}143.44 \\
(0.66)\end{array}$ & $\begin{array}{l}73.078 \\
(4.14)\end{array}$ & $\begin{array}{l}1.22 \\
(0.04)\end{array}$ & $\begin{array}{c}0.30 \\
(0.04)\end{array}$ & $\begin{array}{l}1.53 \\
(0.07)\end{array}$ & $\begin{array}{l}61.55 \\
(3.60)\end{array}$ & $\begin{array}{c}0.34 \\
(0.00)\end{array}$ & $\begin{array}{c}0.44 \\
(0.00)\end{array}$ \\
\hline
\end{tabular}

Values in parenthesis represent the standard deviations. a) $\bar{X}, X_{\mathrm{cr}}, V_{\text {lowP }}, V_{\text {highp }}, V_{\text {total }}, \varepsilon, \rho_{\mathrm{b}}, \rho_{\mathrm{t}}$ were previously reported. ${ }^{14)}$

a)

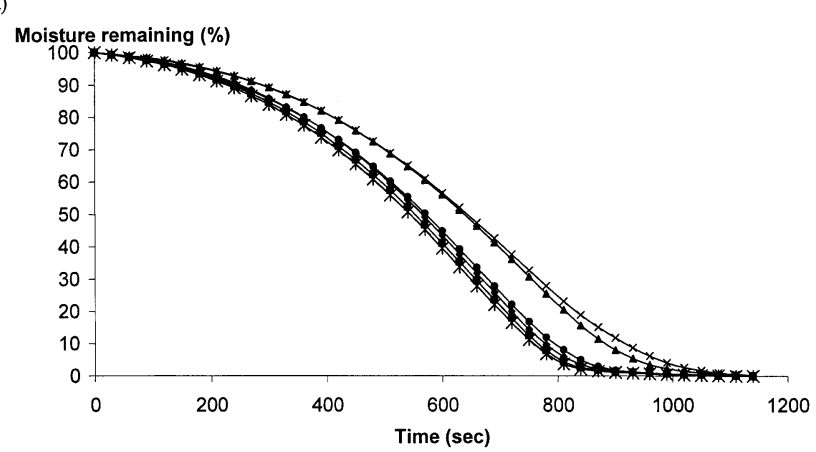

b)

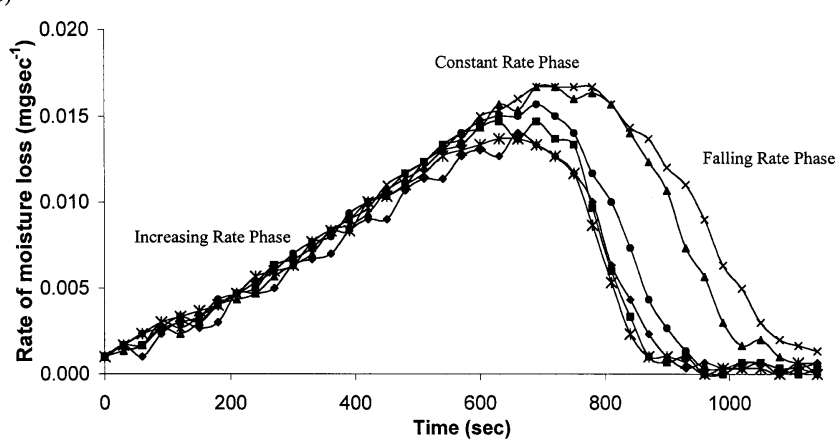

Fig. 2. Variation of (a) Percent Moisture Loss and (b) Rate of Moisture Loss with Time for $(\diamond)$ Avicel PH 101, (ם) Avicel PH 102, (A) Avicel PH 301, (×) Avicel PH 302, (*) Pharmacel 101 and (O) Pharmacel 102

which occurred from a constant drying area of the bed surface where capillary water from within the bed rose readily to replenish the moisture evaporated from the surface of the bed.

Unlike in bed drying situations, however, drying condition of the granulates was unlikely to possess substantial powder depth to produce any sustained capillary rise to exhibit a prolonged constant rate phase. Thus, the constant rate phases were generally very short, dependent on the available interstitial water present within the granulates.

By the end of the constant rate phase, only water that was less accessible or physically bound to the solid particles (structured water) was expected to remain in the granulates.

The falling rates can be seen to fall with varying slopes in PH 301 and PH 302 although the differences may not appear to be very obvious (Fig. 2b). The first falling rate phase coincided with moisture loss from less accessible crevices where the vapor has to diffuse out to be removed by the air stream. The second falling rate phase required additional energy to break the hydrogen bonds between the water molecules and the anhydroglucose units in MCC in order to release the bound water. Loss of this water was reflected in the second falling rate phase on the DTG curves.

Water evaporation is responsible for both mass loss and heat absorption. The latent heat of evaporation taken up effectively cools the surfaces containing moisture. As the amount of moisture present decreases, especially after the constant rate phase, the amount of latent heat absorbed is correspondingly reduced. Consequently, the sample would be heated up beyond the wet bulb temperature, approaching that of the drying air. As the substrate surface is heated up, evaporation would be facilitated. This accounted for the sharper fall in the slope of the second falling phase despite structured water being more tightly bound to the particle surfaces. Moisture loss from the wet granulates was presented diagrammatically in Chart 1.

It was also observed (Fig. 2b) that the curves for the high density MCC grades of Avicel PH 301 and PH 302 were clearly displaced towards the right, with more gradual slopes, indicating that the rates of moisture loss proceeded at slower rates compared to the lower density grades. The rank order of the slopes was as follows: $\mathrm{PH} 101=\mathrm{PH} 102 \geq$ Pharmacel $101=$ Pharmacel 102 $>$ PH 301 $>$ PH 302.

The order of the slopes coincided with the rank order of crystallinity (Table 1) although the slopes of PH 101, PH 102 and Pharmacel 101 and Pharmacel 102 were not well differentiated. It appeared that crystallinity had an effect on the rate of moisture loss from the wet granulates. More crystalline MCC grades tended to lose water less readily.

Moisture was reported not to be taken up well by the crystalline regions of MCC and was believed to be almost predominantly bound to the amorphous regions. ${ }^{16,17)}$ However, water could still be accommodated in the gaps between the microfibrils and also in the less ordered interlinking areas between elementary crystallites in the basic fibrils. ${ }^{18)}$ Water located in these so called "intra-crystalline" regions would be much harder to lose due to poorer accessibility since they were present in the relatively more ordered crystalline core of the MCC particles compared to those associated with the 
amorphous components.

Area under the falling rate phase corresponded to the amount of structured water associated with the MCC particles. The $\% \mathrm{H}_{2} \mathrm{O}_{(\mathrm{s})}$ values are shown in Table 1, whereas the amounts of structured water per unit weight of MCC powder are shown in Table 2. It was observed that the higher amounts of structured water were associated with the smaller particle size grades of MCC.

Water Vapor Sorption The water vapor sorption isotherms for the 4 Avicel MCC grades are presented in Fig. 3. By fitting the isotherms into the GAB equation using linear regression, the constants in the equation were obtained.

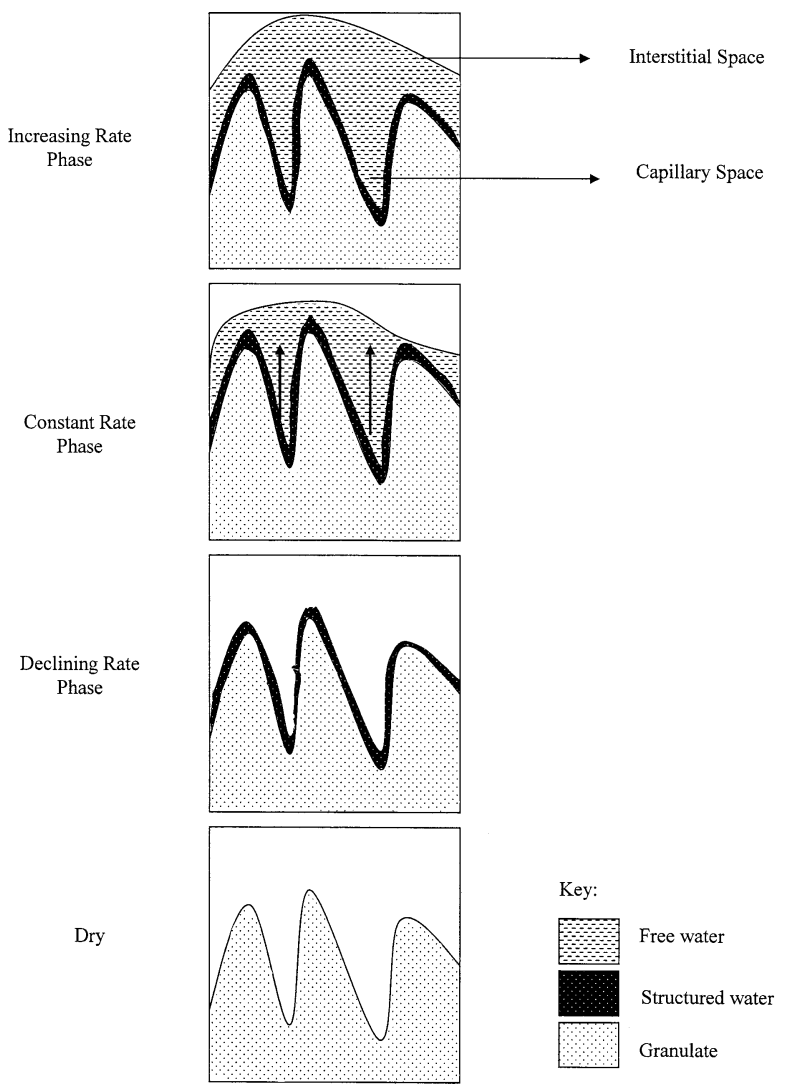

Chart 1. Diagrammatic Presentation of the Moisture Loss from the Wet Granulates
In particular, the monolayer capacity, $M_{\mathrm{o}}$, which reflected the area of available binding surface, was determined for the various MCC grades (Table 2). As previously mentioned, moisture was mostly taken up by the amorphous component of the MCC. Hence, it was more appropriate to correct the calculated $M_{\mathrm{o}}$ values for the fraction of non-crystalline component. ${ }^{19)}$ Corrected $M_{\mathrm{o}}$ values, $M_{\mathrm{o}(\mathrm{corr})}$, were also presented in Table 2.

By quantifying the amount of structured water per unit weight of MCC powder and expressing this as a quotient of $M_{\mathrm{o}(\mathrm{corr})}$, it is possible to estimate the relative thickness of the structured water. The results showed that the structured water formed approximately 2 layers on the surface of the MCC particles, a finding that is close to another previously reported. ${ }^{12)}$ Particle size also appeared to have an effect on the amount and the number of layers of the structured water formed. The larger particle size grades were also shown to give lower values for the number of layers of structured water and this could be the result of relatively less available surface areas for the water molecules to bind to the hydroxyl groups present on the anhydroglucose units of the MCC particles. It is also likely that larger particles have flatter surfaces which were more amenable to the formation of thinner moisture films, especially for the high density MCC grades. Curved surfaces, of relatively greater abundance with smaller particles, will expose a greater level of surface imperfections en-

Table 2. Amount of Structured Water per Unit Weight of Sample and Monolayer Capacities of MCC Grades ${ }^{a}$

\begin{tabular}{ccccc}
\hline \hline \multirow{2}{*}{ MCC } & \multicolumn{2}{c}{ Absorption (g) } & $\begin{array}{c}\mathrm{g} \mathrm{H}_{2} \mathrm{O}_{(\mathrm{s})} / \\
\text { g dry sample }\end{array}$ & $\begin{array}{c}\mathrm{g} \mathrm{H}_{2} \mathrm{O}_{(\mathrm{s})} / \\
\mathrm{g} M_{\text {o(corr })}\end{array}$ \\
\cline { 2 - 5 } & $M_{\mathrm{o}}$ & $M_{\mathrm{o} \text { (corr) }}$ & & \\
\hline \multirow{2}{*}{ PH 101 } & 0.034 & 0.112 & 0.2454 & 2.1984 \\
& $(0.001)$ & $(0.00194)$ & $(0.0374)$ & $(0.365)$ \\
PH 102 & 0.036 & 0.118 & 0.206 & 1.742 \\
& $(0.000)$ & $(0.00128)$ & $(0.0417)$ & $(0.368)$ \\
PH 301 & 0.029 & 0.124 & 0.2598 & 2.098 \\
& $(0.000)$ & $(0.00127)$ & $(0.0248)$ & $(0.2034)$ \\
PH 302 & 0.033 & 0.216 & 0.2112 & 0.9798 \\
& $(0.0005)$ & $(0.00293)$ & $(0.0103)$ & $(0.0415)$ \\
\hline
\end{tabular}

Values in parenthesis represent the standard deviations. $a$ ) The $\mathrm{g}_{2} \mathrm{O}_{(\mathrm{s})} / \mathrm{g} M_{\mathrm{o}(\mathrm{corr})}$ values between the $4 \mathrm{MCC}$ grades were found to be statistically significant (one way ANOVA, $p<0.05$ ).

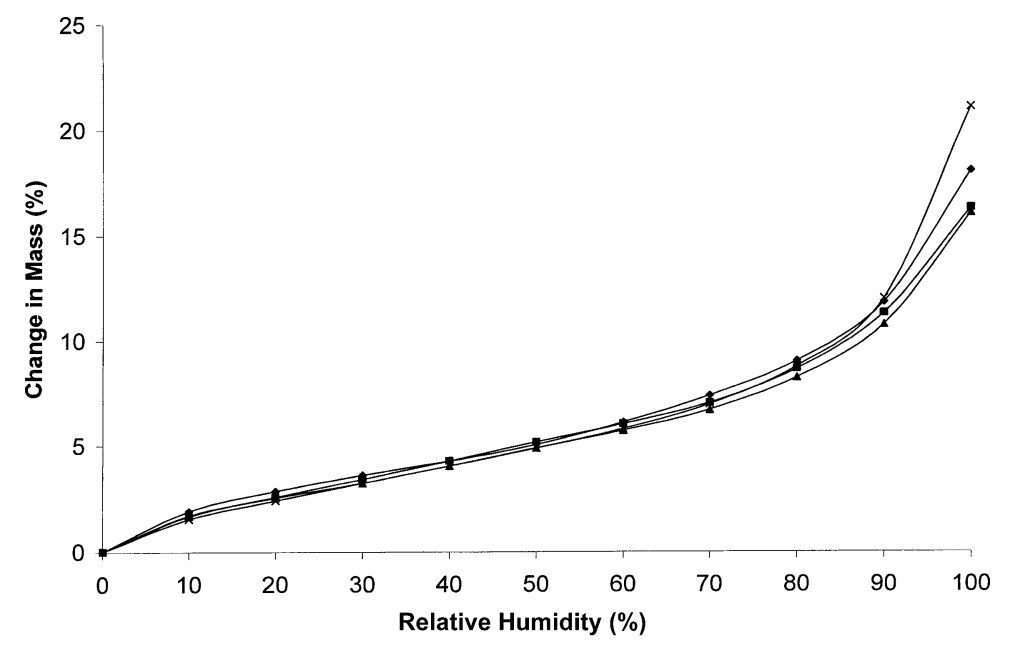

Fig. 3. Water Vapor Sorption Isotherms for ( 
Avicel PH 101

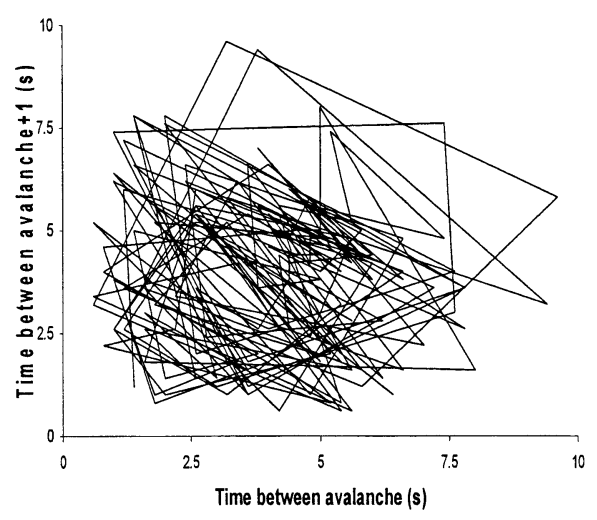

Avicel PH 301

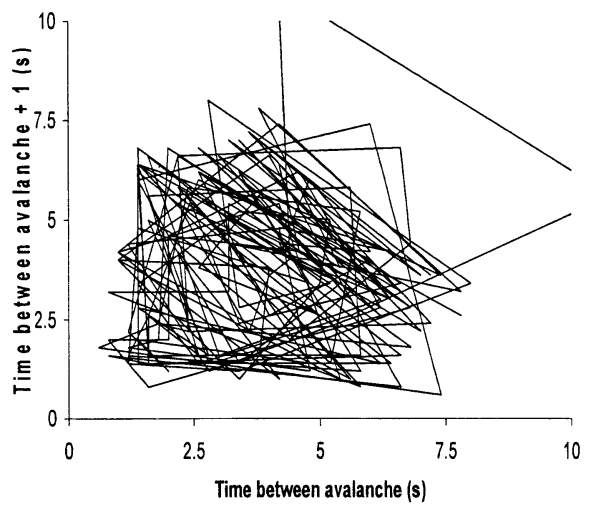

Pharmacel 101

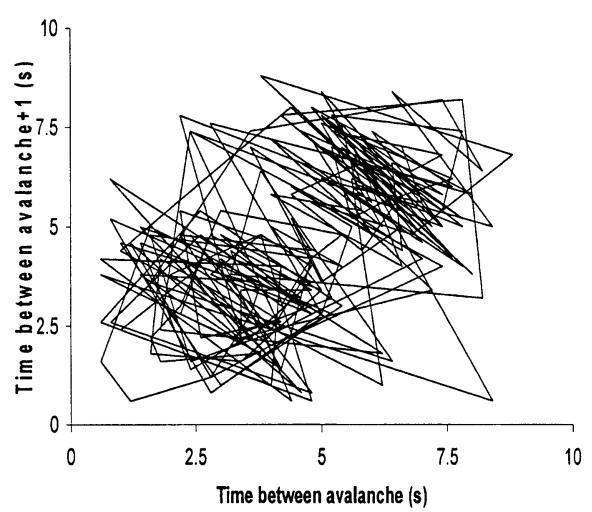

Fig. 4. Strange Attractor Plots of MCC Grades

trapping correspondingly higher specific amounts of structured water. Crystallinity levels did not appear to have any significant effect on the number of layers formed.

Flow Properties of MCCs Determined by Avalanching Method The strange attractor plots of the $6 \mathrm{MCC}$ grades for drum speed of one rotation per $120 \mathrm{~s}$ were presented in Fig. 4. This is the recommended speed for general analysis since faster speeds were used for aeration of powders and slower speeds for static avalanching of free-flowing materials. The points on the strange attractor plots were focused onto a central point known as point of attraction, which represented the mean time between avalanches. Free flowing powders would have more successive avalanches, producing coordinates closer to its point of attraction, thus producing a
Avicel PH 102

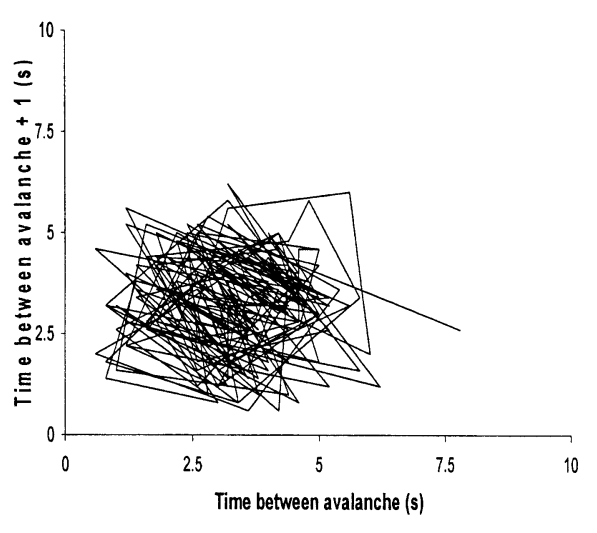

Avicel PH 302
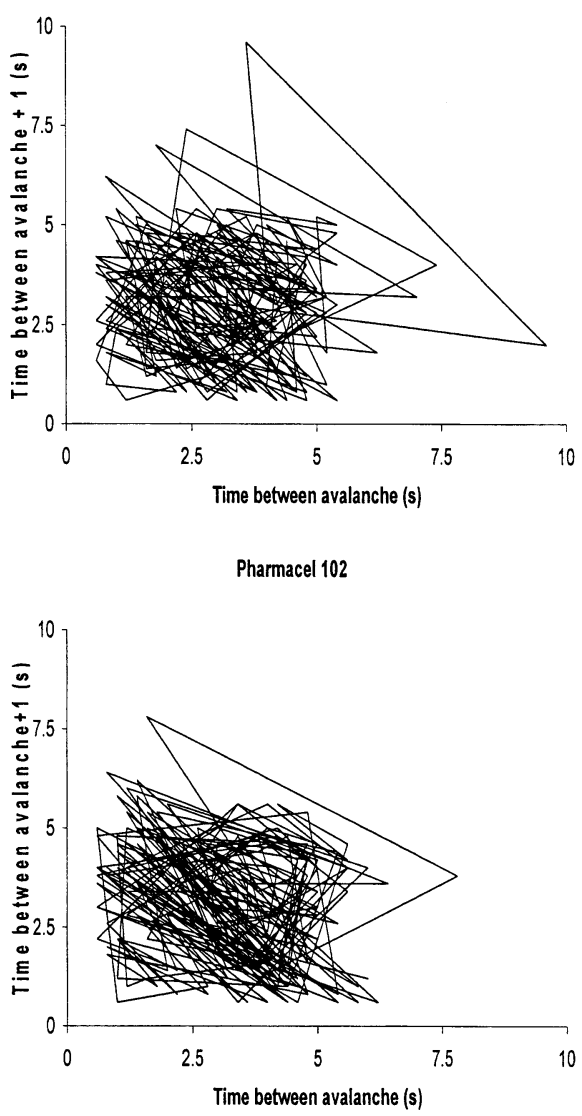

dense pattern that was close to the origin.

According to their calculated flow indices, the flow properties of powders were ranked as Avicel $\mathrm{PH} 102>\mathrm{PH}$ $302>$ Pharmacel $102>$ Pharmacel $101>$ PH 101 $>$ PH 301. At most drum speeds tested, the mean times to avalanche were lower for Avicel PH 102, PH 302 and Pharmacel 102 (Table 3 ). In addition, they also created denser patterns on the scatter plot, indicating that they possessed more desirable flow than the other 3 grades. The explanation for this observation was the difference in particle size between the 3 groups of MCCs. As previously mentioned, these 3 MCC grades were larger in particle size, which inadvertently resulted in a reduction of contact areas, electrostatic and frictional forces that were responsible for increasing the resistance to particle 
flow. This was further supported by the correlation results whereby the flow indices were inversely correlated to particle size, indicating that the larger particle size grades of MCC would exhibit better flow properties (Table 4) since larger particle size grades possessed smaller flow indices. Once again, the influence of surface area and particle size could not be neglected. The characteristic strange attractor plots also provided the fingerprint flow properties for the six

Table 3. Mean Time to Avalanche and Standard Deviations of $4 \mathrm{MCC}$ Grades Tested at Different Drum Speeds

\begin{tabular}{cccl}
\hline \hline MCC & $\begin{array}{c}\text { Drum speed } \\
\text { (s rotation }{ }^{-1} \text { ) }\end{array}$ & $\begin{array}{c}\text { Mean time to } \\
\text { avalanche (s) }\end{array}$ & Scatter (s) \\
\hline PH 101 & 60 & 2.70 & 0.959 \\
PH 102 & 60 & 2.07 & 0.744 \\
PH 301 & 60 & 2.51 & 1.15 \\
PH 302 & 60 & 1.84 & 0.73 \\
Pharmacel 101 & 60 & 3.02 & 0.811 \\
Pharmacel 102 & 60 & 2.13 & 0.759 \\
PH 101 & 75 & 2.75 & 1.18 \\
PH 102 & 75 & 2.30 & 0.964 \\
PH 301 & 75 & 2.76 & 1.26 \\
PH 302 & 75 & 2.36 & 0.808 \\
Pharmacel 101 & 75 & 3.68 & 1.11 \\
Pharmacel 102 & 75 & 2.45 & 0.966 \\
PH 101 & 100 & 3.40 & 1.50 \\
PH 102 & 100 & 2.85 & 1.14 \\
PH 301 & 100 & 3.32 & 1.65 \\
PH 302 & 100 & 2.68 & 1.23 \\
Pharmacel 101 & 100 & 4.78 & 1.53 \\
Pharmacel 102 & 100 & 3.01 & 1.19 \\
PH 101 & 120 & 3.91 & 2.02 \\
PH 102 & 120 & 3.29 & 1.31 \\
PH 301 & 120 & 3.78 & 2.07 \\
PH 302 & 120 & 3.03 & 1.61 \\
Pharmacel 101 & 120 & 5.88 & 1.58 \\
Pharmacel 102 & 120 & 3.19 & 1.58 \\
PH 101 & 150 & 4.56 & 2.38 \\
PH 102 & 150 & 3.35 & 1.70 \\
PH 301 & 150 & 4.73 & 2.68 \\
PH 302 & 150 & 3.55 & 1.76 \\
Pharmacel 101 & 150 & 6.79 & 2.38 \\
Pharmacel 102 & 150 & 3.91 & 1.96 \\
PH 101 & 200 & 5.39 & 3.40 \\
PH 102 & 200 & 4.12 & 2.37 \\
PH 301 & 200 & 4.99 & 3.33 \\
PH 302 & 200 & 4.27 & 2.47 \\
Pharmacel 101 & 200 & 9.04 & 3.29 \\
Pharmacel 102 & 200 & 4.69 & 2.58 \\
PH 101 & 240 & 6.43 & 4.04 \\
PH 102 & 240 & 4.96 & 2.96 \\
PH 301 & 240 & 6.66 & 4.06 \\
PH 302 & 240 & 5.03 & 2.98 \\
Pharmacel 101 & 240 & 10.7 & 3.52 \\
Pharmacel 102 & 240 & & \\
\hline & & & \\
\hline
\end{tabular}

grades of MCC.

Correlation between $T_{50 \%}, \% \mathrm{H}_{2} \mathrm{O}_{(\mathrm{s})}$ and Physical Properties of MCC Grades Correlation results were presented in Table 4. $T_{50 \%}$ was significantly correlated with pore volumes and densities of the MCC grades. These were the important properties governing the ease of water release from $\mathrm{MCC}$ as it seemed that less porous MCC grades which were of higher crystallinities and densities released bound moisture less readily. Relative ease of water release was reflected in the lower $T_{50 \%}$ values.

Crystallinity was significantly correlated to $T_{50 \%}$ (Table 4 ) as it affected the amount and ease of moisture uptake by the MCC particles. More crystalline MCCs would be expected to accommodate less of the added moisture since the proportion of anhydroglucose units in the amorphous regions of cellulose molecules are identical. ${ }^{20)}$ Larger amounts of the added water would be present in MCC as loosely bound or interstitial water. Consequently, longer heating times were required to lose $50 \%$ of the moisture in the granulates, as reflected in the higher $T_{50 \%}$ values. The correlation results for pore volumes could also be explained similarly.

The denser grades of MCC were composed of smaller microfibril units which were more tightly packed. This accounted for the greater abundance of inter-fibrillar spaces for water entrapment. Not only could more moisture be entrapped, the evaporation during drying stage would also be relatively more hindered. This explains in part the anomaly of the higher moisture uptake in the sorption isotherm by $\mathrm{PH}$ 302 which is the most crystalline. The effects of packing exerted a more dominant influence than crystallinity in moisture uptake and loss.

The percentage of structured water, $\% \mathrm{H}_{2} \mathrm{O}_{(\mathrm{s})}$, were found to be significantly correlated to particle size and flow indices of the MCC powders (Table 4). As explained earlier, particle size directly affects the available surface areas for binding of water molecules which is subsequently reflected in the \% $\mathrm{H}_{2} \mathrm{O}_{(\mathrm{s})}$ values.

\section{Conclusions}

The usefulness of thermo-gravimetric analysis in illustrating the sequential loss of water from wet MCC granulates and determining the proportion of structured water associated with the MCC particles was explored and assessed in this study.

Drying profiles of the MCC grades were characterized by the $T_{50 \%}$ values reflected the relative ease of moisture loss from the wet granulates. Denser MCC grades generally required longer heating time for the removal of half their free and loosely bound water. This was attributed to their higher crystallinity, densities and smaller pore volumes. Simple in-

Table 4. Correlation Analysis of $T_{50 \%}$ with Physical Properties of Various MCC Grades

\begin{tabular}{|c|c|c|c|c|c|c|c|c|c|}
\hline & \multirow{2}{*}{ Flow index } & \multirow{2}{*}{$\begin{array}{l}\text { Size } \\
\bar{X}\end{array}$} & \multirow[b]{2}{*}{$X_{\mathrm{cr}}$} & \multicolumn{4}{|c|}{ Micromeritic property } & \multicolumn{2}{|c|}{ Density } \\
\hline & & & & $V_{\text {lowP }}$ & $V_{\text {highP }}$ & $V_{\text {total }}$ & $\varepsilon$ & $\rho_{\mathrm{b}}$ & $\rho_{\mathrm{t}}$ \\
\hline$T_{50 \%}$ & - & - & $\begin{array}{c}0.869^{a)} \\
(0.025)\end{array}$ & $\begin{array}{c}-0.929^{b)} \\
(0.007)\end{array}$ & $\begin{array}{c}-0.758 \\
(0.080)\end{array}$ & $\begin{array}{c}-0.992^{b)} \\
(0.000)\end{array}$ & $\begin{array}{c}-0.688 \\
(0.130)\end{array}$ & $\begin{array}{c}0.993^{b)} \\
(0.001)\end{array}$ & $\begin{array}{r}0.98^{b)} \\
(0.001)\end{array}$ \\
\hline$\% \mathrm{H}_{2} \mathrm{O}_{(\mathrm{s})}$ & $\begin{array}{c}0.832^{a)} \\
(0.040)\end{array}$ & $\begin{array}{c}-0.888^{a)} \\
(0.018)\end{array}$ & - & - & - & - & - & - & - \\
\hline
\end{tabular}

Values in parenthesis represent probabilities. $a$ ) Correlation significant at 0.05 level (2-tailed), $b$ ) correlation significant at 0.01 level (2-tailed). 
tegration of the areas under the falling phase of the DTG curves enabled the amount of structured water to be quantified.

Monolayer capacities of the respective MCC grades were determined from the water vapor sorption isotherm using the GAB equation. Structured water appeared to extend out to twice of $M_{\mathrm{o}}$ for the smaller particle size MCC grades.

Thermo-gravimetric analysis provided a simple and efficient method of quantifying the proportion of bound water associated with solid particles. Together with small sample requirements and a microbalance of high sensitivity, analysis could be performed with great precision and accuracy.

Avalanche flow data further reiterated the importance of particle size and surface area. The mean times to avalanche and flow indices were used to characterize powder flow. A shorter mean time taken to avalanche and small flow index were indicative of good flow properties. Powders from small particle size grades of MCC possessed higher flow indices and thus exhibited poorer flow. Powder flow using the avalanching method was able to differentiate between the flow properties of MCC grades and demonstrate the effect of particle size on ease of flow.

Acknowledgements The authors would like to thank Shimadzu Asia Pacific Limited for the use of DTG $60 \mathrm{H}$ and Nestlé R\&D Center (Pte) Ltd, Singapore, for the use of DVS-1000.

\section{References and Notes}

1) Heng P. W. S., Koo O. M. Y., Pharm. Res., 18, 480-487 (2001).
2) Whiteman M., Yarwood R. J., Powder Tech., 54, 71-74 (1988).

3) Chatrath M., Staniforth J. N., Herbert I., Luk S. Y., Richards G., J. Pharm. Pharmacol., 43, 7P (1991).

4) Landin M., Martinez-Pacheo R., Gomez-Amoza J. L., Souto C., Concheiro A., Rowe R. C., Int. J. Pharmaceut., 91, 133-141 (1993).

5) Rowe R. C., McKillop A. G., Bray D., Int. J. Pharmaceut., 101, 169172 (1994).

6) Parker M. D., York P., Rowe R. C., Int. J. Pharmaceut., 80, 179-190 (1992).

7) Giron D., J. Pharmaceut. Biomed., 4, 755-770 (1996).

8) Giron D., J. Therm. Anal. Calorim., 68, 335-357 (2002).

9) Fielden K. E., Newton J. M., O'Brien P., Rowe R. C., J. Pharm. Pharmacol., 40, $674-678$ (1988).

10) Picker K. M., Hoag S. W., J. Pharm. Sci., 91, 343-349 (2000),

11) Blair T. C., Buckton G., Beezer A. E., Bloomfield S. F., Int. J. Pharmaceut., 63, 251-257 (1990).

12) Zografi G., Kontny M. J., Pharm. Res., 3, 187-193 (1986).

13) Brunauer S., Emmett R. H., Teller E., J. Am. Chem. Soc., 60, 309319 (1938).

14) Koo O. M. Y., M. Sc (Pharm) Thesis, National University of Singapore, Singapore, 2002.

15) Lavoie F., Cartilier L., Thibert R., Pharm. Res., 19, 887-893 (2002).

16) Honeyman J., "Recent Advances in the Chemistry of Cellulose and Starch," Interscience, New York, 1959, pp. 147-187, 240-264.

17) Stamm A. J., "Wood and Cellulose Science," Ronald Press, New York, 1964, pp. 41-49, 142-165, 166-171, 186-200, 389.

18) Krässig H. A., "Cellulose: Structure, Accessibility and Reactivity," Gordon and Breach Science Publishers, Switzerland, 1993, p. 177.

19) Zografi G., Kontny M. J., Yang A. Y. S., Brenner G. S., Int. J. Pharmaceut., 18, 99-116 (1984).

20) Parker M. D., Rowe R. C., Powder Tech., 65, 273-281 (1991). 